\title{
A zona cinza \\ Ordem criminosa e autodefesa armada no México
}

Antonio Fuentes Díaz* https://orcid.org/0000-0002-4575-9462

Introdução

Em 2013, em várias cidades e povoados do estado de Michoacán, no México, apareceram repentinamente grupos de civis armados, organizados para a defesa de territórios, bens e pessoas, contra a extorsão e violência praticadas pelo crime organizado. $\mathrm{O}$ fenômeno teve uma rápida expansão territorial, gerando 45 grupos armados em distintos municípios do estado durante aquele ano, com cerca de 20 mil cidadãos armados.

No México, como nas Rondas Comunitárias do Peru' (Starn, 1999), os grupos de defesa comunitária foram formados em resposta ao ambiente de insegurança. Nos anos de 1990, apareceram as primeiras organizaçóes defensivas nos estados de Morelos e Aguascalientes, em resposta ao clima promovido pelos crimes comuns. As estatísticas sobre o crime na década indicaram um aumento dos delitos contra a propriedade e as pessoas (Schwartz, 1998), com sequestros e homicídios três vezes maiores que a média mundial (Inegi, 2014).

* Universidade Autônoma de Puebla (UAP), Puebla, México.

1. A defesa comunitária ocorreu nas décadas de 1970 e 1980, nas zonas rurais da Colômbia, Guatemala e Peru. Embora as organizações funcionassem de maneira defensiva, elas apresentam diferenças em relação aos motivos para sua formação e ao contexto histórico em que foram manifestadas. No Peru, as Rondas Campesinas surgiram com o auge de delitos e a desconfiança com a justiça oficial, suprindo funções de segurança e estabelecendo um sistema de justiça alternativo (Starn, 1999). 
Durante a presidência de Felipe Calderón (2006-2012), ocorreu uma mudança qualitativa na insegurança, a partir dos conflitos entre os grupos do narcotráfico e as políticas públicas para combatê-los ${ }^{2}$; bem como por uma mudança na natureza do narcotráfico que quebrou o histórico equilíbrio entre atividades ilegais e as comunidades. Essa mudança na insegurança e a quebra do equilíbrio estabeleceram o clima favorável para o surgimento do movimento armado de defesas comunitárias em Michoacán em 2013 por meio da criação de uma arena de disputa entre diversos atores em busca de uma recomposição político regional, em que múltiplos atores têm disputado diferentes conexões do uso legítimo da violência e da regulação social, em uma zona cinza caracterizada pela indistinção entre Estado e criminalidade.

Dentro da categoria defesa comunitária estão incluídas as distintas formas organizadas para fins de defesa, de acordo com a própria denominação dada pelos grupos. Assim, o termo abrange especificamente duas formas expressas no contexto michoacano: polícias comunitárias e grupos de autodefesa ${ }^{3}$. A diferença entre polícia comunitária e autodefesa, para o caso de Michoacán, é a forma como a organização é sustentada. A primeira se encontra legalmente reconhecida como parte dos usos e costumes dos povos originários, com base no artigo $2^{\circ}$ da Constituição, referido à autodeterminação de povos originários, e obedece a uma tomada de decisões baseada em assembleias. A segunda foi uma organização armada sem componente étnico, articulada sob a liderança de figuras carismáticas e com base na defesa da integridade pessoal e do patrimônio (Fuentes Díaz, 2015a) (Gráfico 2).

\section{Metodologia}

O artigo refere as experiências dos grupos de autodefesa que surgiram nos povoados de Tepalcatepec, La Ruana e Buenavista, localizados em Tierra Caliente, em Michoacán ${ }^{4}$ e situa seu surgimento nos processos incertos de formação do Estado em termos de produção de imaginários de ordem e de uma zona cinza. A informação apresentada foi reunida durante onze viagens de campo realizadas ente 2013 e 2016, três por ano, em estadias de três a quatro semanas nas áreas de pesquisa,

2. A "Guerra contra o Narcotráfico" foi uma política de segurança que teve um enfoque militar consistente em recuperar áreas que haviam sido ocupadas por organizações de narcotráfico. Segundo pesquisadores e organizações de direitos humanos, o número de mortes vinculadas a essa política superou 100 mil pessoas assassinadas (Escalante, 2011) e o número de desaparecidos foi, pelo menos, de 28.161 (RNPED, 2016).

3. Existe uma terceira forma ainda pouco documentada: os grupos privados armados.

4. “Tierra Caliente" é um vale entre 300 e $800 \mathrm{~m}$. de altitude, com temperaturas que vão de $28^{\circ} \mathrm{C}$ a $50^{\circ} \mathrm{C}$, que se estende pelos estados de Michoacán, Guerrero e Estado do México. Michoacán possui uma população de 490.000 habitantes e suas principais cidades são Apatzingán, Buenavista, Nueva Italia, Huetamo, Tepalcatepec e La Ruana (Inegi, 2010). 
nas quais, além da observação participante, foram feitas 35 entrevistas com líderes dos grupos de autodefesa e polícia comunitária, líderes locais como professores, médicos, autoridades tradicionais, representantes de partidos políticos, autoridades municipais, organizações religiosas e residentes envolvidos em organizações de defesa comunitária.

As entrevistas foram realizadas nas casas, em reuniões de trabalho ou em festas públicas, como os aniversários da revolta armada. $\mathrm{O}$ trabalho de campo em zonas de conflito é complexo e tem sido possível através do uso de redes de informantes que foram estabelecidas por meio de associações profissionais, principalmente professores, médicos, a Igreja Católica e associações civis locais, garantindo o sigilo dos informantes e tentando não expô-los quando as condições não foram adequadas para pesquisa de campo. Os nomes dos informantes neste artigo foram modificados.

Neste artigo mencionam-se entrevistas realizadas em outras regiões de Michoacán, onde também ocorreu a formação de defesas comunitárias, como Peribán e Tancítaro. A informação foi integrada com a consulta da base de dados do Instituto Nacional de Estatística, Geografia e Informática (Inegi) sobre o perfil sociodemográfico das comunidades e com uma revisão de jornais de circulação regional e nacional.

\section{O papel em constante transformação do narcotráfico}

Para entender o surgimento de grupos defensivos em Michoacán, é necessário entender a transformação dos grupos de narcotráfico na região em uma nova forma de operação que interrompeu a reciprocidade entre o ilegalismo e as comunidades.

O cultivo de drogas no México remonta ao século XIX, com a migração da população da China para Sinaloa, que introduziu cultivos relacionados com seus fins medicinais e de lazer, como a papoula. No início do século xx o cultivo de ópio e maconha começou como uma atividade de subsistência familiar nas comunidades pobres das terras altas de Sinaloa (Grillo, 2011), onde pequenos produtores cultivavam papoula e maconha para um mercado regional de pequenas projeções, tendo a sua primeira expansão no contexto da Segunda Guerra Mundial, quando a demanda por opiáceos para a fabricação de anestésicos impulsionou o plantio e o tráfico em direção aos Estados Unidos (Astorga, 2015). No lapso de quatro décadas, de 1940 a 1980, o cultivo de substâncias ilegais levou a uma mudança consistente no surgimento de empresas familiares que controlavam grandes partes do Sinaloa e outros estados do Pacífico, como Michoacán e Guerrero, bem como as rotas em sua comercialização para os Estados Unidos, favorecidas nos anos de 1970 pelo aumento do consumo de estimulantes pelo movimento contracultural naquele país. Nos anos de 1980, as organizações colombianas haviam controlado a rota de cocaína através do 
Caribe com acesso aos Estados Unidos pela Flórida, mas a política de proibição da administração Reagan (1981-1989) obrigou o reencaminhamento para o Pacífico. Isso trouxe um novo papel para as organizações mexicanas dessa região no tráfico para os Estados Unidos e levou tais organizações a entrar no negócio da cocaína juntando-se com organizações colombianas (Valdés, 2013). Nesses anos os portos de Michoacán começaram a ter uma função estratégica na geopolítica de drogas, sob o controle da Organização da Sinaloa. Nos anos de 1990, a prisão de seus líderes fragmentou a Organização da Sinaloa em pequenos grupos e outras lideranças apareceram, recompondo o acesso de drogas através do Golfo do México ("Cartel do Golfo") e disputando o controle sobre as metanfetaminas.

O narcotráfico no México hoje é caracterizado pela fragmentação dos grandes grupos e a crescente demanda por drogas sintéticas. Essa mudança significou a diversificação de atividades que vão além do cultivo e transporte de substâncias ilegais, para incluir uma voraz atividade comercial criminosa (Ravelo, 2009).

A diversificação do narcotráfico deve ser entendida como parte de uma complexa rede de fatores que incluem o conflito entre as organizações, as políticas de controle tanto no México quanto nos Estados Unidos ("Guerra contra o narcotráfico" e militarização da fronteira, por exemplo), a história política das regiões onde a produção se baseia e as mudanças macroestruturais que ocorreram no México desde a implementação do modelo de desenvolvimento baseado nas políticas de liberalização, com a entrada no Acordo Geral sobre Tarifas Alfandegárias e Comércio (GATT) e o Tratado de Livre Comércio da América do Norte (TLCAN). Esse contexto é importante porque nos permite diferenciar os fatores que deram ao narcotráfico seu perfil tradicional daqueles da nova fase de operação, caracterizada por sua transformação em uma corporação global, com uma ampla diversificação de atividades lucrativas e uma grande capacidade no uso da força.

$\mathrm{O}$ tráfico de drogas como forma de atividade econômica se adaptou às novas formas de concorrência no mercado que surgiu com a abertura ao comércio internacional. Durante os anos dourados do narcotráfico no México (1940-1980), a atividade ilegal foi regulada e centralizada pela Diretoria Federal de Segurança (DFS), órgão de inteligência do Estado Mexicano naquele momento. Esse modelo de regulamentação envolveu a subordinação das organizações de narcotraficantes à DFS através de concessões e participação nas utilidades, sob o compromisso de um comportamento criminoso "civilizado", que afetasse o menos possível as comunidades (Valdés, 2013). Nos anos de 1990, as novas relações econômicas estabelecidas com os Estados Unidos, o desaparecimento do DFS e a fragmentação do cartel de Sinaloa em suborganizações deram fim a esse modelo de controle centralizado (Flores, 2009). Anos mais tarde, a descentralização administrativa do Estado, baseada no artigo 
115 da Constituição Política do México, deu aos estados e municípios uma maior margem de manobra na gestão dos gastos públicos, rearticulando um regime autoritário subnacional (Gibson, 2013), o que teve consequências para a reorganização da relação Estado-narcotráfico no âmbito local (Astorga, 2015).

Da mesma forma, a desregulamentação estatal da economia, como paradigma central do neoliberalismo, e a descentralização dos recursos aos governos estatais e locais levaram ao aparecimento de novos atores políticos e econômicos, alguns dos quais logo disputaram a soberania e o monopólio estatal do uso da força. É nesse ponto que o funcionamento dos grupos de narcotráfico assumiu novas características. "Transformados em empresas neoliberais, capitalizaram condições estruturais como a falta de oportunidades para gerar ascensão social por meios ilegais" (Fuentes Díaz, 2015b). Essa mudança os levou a diversificar suas atividades criminosas mediante a extorsão, o sequestro, o controle das minas de ferro, a comercialização de cultivos e a extração ilegal de madeira nos bosques de propriedade comunitária, tornando-se corporações do crime organizado. Essas mudanças interromperam a histórica relação equilibrada que havia no local entre a ilegalidade, as comunidades e o Estado. Isso levou à formação de grupos armados de defesa no início de 2013 em Michoacán.

\section{Narcotráfico em Michoacán}

Michoacán foi uma região de agricultura comercial extensa desde o século XIX, onde floresceu o modelo de ranchos e fazendas, baseadas na produção de gado, de arroz e de frutas cítricas. Sob o governo de Lázaro Cárdenas (1934-1940), várias dessas fazendas foram desapropriadas e divididas em ejidos coletivos 5 . Durante os seis anos de governo de Miguel Alemán (1946-1952), foi incentivada a criação de projetos de desenvolvimento agrícola e industrial, através da implementação de obras de irrigação, escolas, campanhas sanitárias, rodovias, ferrovias e telégrafo, sob o projeto da Bacia do Rio de Tepalcatepec, que posteriormente, nos anos de 1970, seria substituído pela Comissão do Balsas ${ }^{6}$. Esses projetos aumentaram as áreas de

5. O Ejido é um tipo de propriedade da terra na legislação mexicana, estabelecida pela reforma agrária que emana da Revolução Mexicana (1910-1917). Esse tipo de propriedade consistia em terra coletiva, indivisa e sem possibilidade de ser vendida ou herdada. $\mathrm{O}$ objetivo inicial da reforma agrária, através do sistema de ejidos, era restaurar a propriedade daqueles que haviam sido desapossados de suas terras. Ela foi formada por comunidades rurais concentradas em um assentamento principal, cuja produção agrícola, pecuária ou florestal tinha fins econômicos, mas também uma parte para o autoconsumo.

6. Os projetos da Bacia do Rio Tepalcatepec (1947) e da Bacia do Rio Balsas (1969) foram projetos de desenvolvimento regional no oeste do México (Jalisco, Colima, Michoacán, Guerrero e Oaxaca), com base na instalação de infraestrutura sanitária, florestal, estradas e pontes, obras de irrigação, barragens, eletricidade, ferrovias, telefone, telégrafo e desenvolvimento agrícola. 
cultivo e formaram uma zona ideal para a agricultura de exportação de algodão, melão e limão (Calderón, 2001).

Existe evidência histórica que o cultivo de estimulantes em Michoacán data dos anos de 1940, a partir do deslocamento de plantadores de Sinaloa ao sul da costa do Pacífico. Na década de 1950, o cultivo de papoula e maconha foi generalizado, inclusive a goma de papoula chegou a ser usada como moeda para operações mercantis (Guerra, 2017). Nas décadas de 1970 e 1980, a crise financeira favoreceu a queda do preço do limão e melão, associado à retirada do incentivo estadual para a produção agrícola. Isto fez com que as perdas fossem remediadas com o cultivo da maconha. Como ocorre em outros territórios, os negócios ilícitos utilizam a infraestrutura agrícola implementada para o desenvolvimento regional. Em Michoacán, o cultivo de estimulantes se apoiou na grande infraestrutura agrícola das comissões de desenvolvimento dos anos de 1940 e 1960.

O modelo de desenvolvimento agrícola de exportação teve benefícios diferenciais, bem-sucedidos para alguns setores camponeses, mas, sobretudo, para as empacotadoras multinacionais e os agentes intermediários, proporcionando uma concentração da riqueza e da terra a partir do arrendamento dos ejidos. Essa concentração gerou o surgimento de fazendeiros dos ejidos que concentraram o poder político regional. Para garantir o controle, utilizaram suas conexões políticas com representantes do Estado e do Exército, mas também, com a formação de milícias armadas e do controle dos Comitês dos ejidos, transformando-os gradualmente em "senhores com poder absoluto" (Meyer, 1987).

Essa produção de chefes locais, sob a figura do senhorio, gerou um tipo de relação política e de sistema local subjacente à forma de controle e regulamentação do narcotráfico, articulando uma ordem ilegal baseada no equilíbrio recíproco entre atividades ilegais e comunidades, dado pelo derramamento de benefícios na base social e em camaradagem com as autoridades do Estado para tolerar os negócios ilegais e o controle local. Esse equilíbrio recíproco criou um tipo de ordem ilegal legítima sob a qual o narcotráfico criou raízes. Essa camaradagem foi documentada em denúncias, enviadas ao secretário da Secretaria de Defesa Nacional na década de 1970 (Guerra, 2017), sobre a cumplicidade com base nos benefícios compartilhados, entre cultivadores de estimulantes e as autoridades do estado encarregadas de seu combate. Isso gerou uma zona de indistinção histórica entre o crime e o Estado. Além disso, um dos códigos em que essa ordem ilegal baseou sua regulamentação foi por meio de uma violência ritual, expressa em vinganças e pistoleirismo e em uma construção da masculinidade baseada no uso de armas.

Dos anos de 1980 até a atualidade, várias organizações criminosas tomaram posse do negócio de substâncias ilegais em diferentes escalas (Gráfico 1). O Cartel do Mi- 
GRÁFICO 1

Sequência de Grupos Criminosos em Michoacán

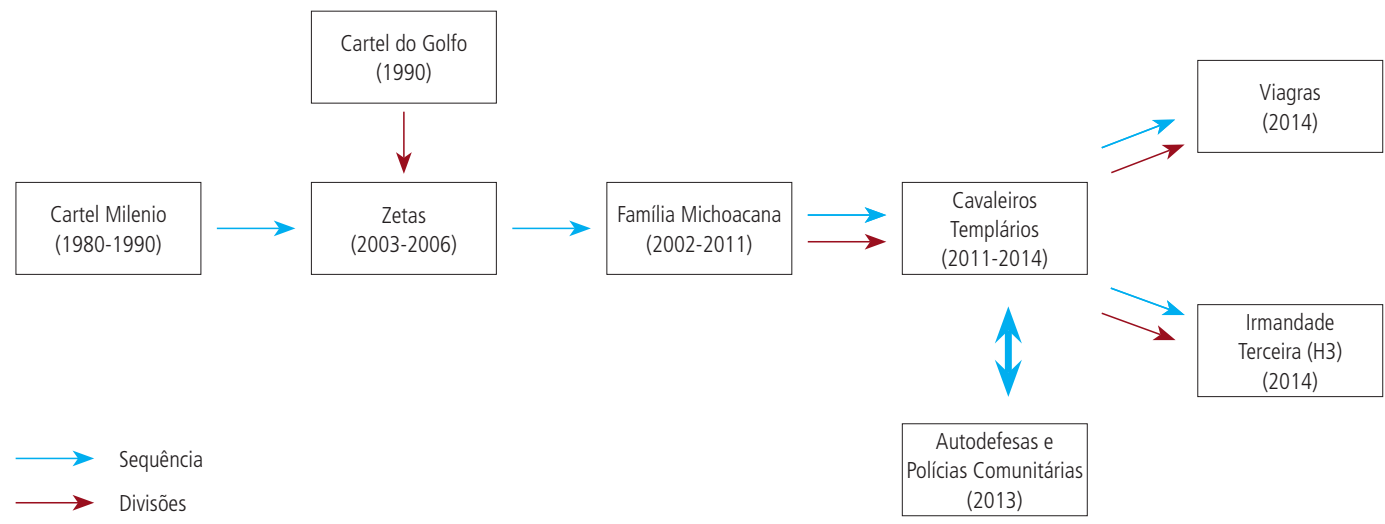

Fonte: Elaboração própria.

lênio foi a organização que concentrou o tráfico de cocaína procedente da Colômbia para os Estados Unidos. Entre as mais significativas dos últimos anos se encontram Os Zetas, grupo de assassinos, constituído por ex-membros do Exército mexicano e do grupo kaibil do Exército da Guatemala, que se separaram da organização denominada $\operatorname{Cartel}^{7}$ do Golfo, envolvendo-se no controle da produção e comercialização de drogas sintéticas em Michoacán. Essa organização ficou conhecida porque, nas disputas pelos lugares, utilizou técnicas de combate de contrainsurgência, como as decapitações e os desmembramentos dos integrantes de grupos rivais, dando às organizações criminosas um novo perfil de operação: a paramilitarização ${ }^{8}$.

Os Zetas foram confrontados e expulsos de Michoacán em 2006 pela Família Michoacana. Essa organização dava ênfase ao fato de que seus membros pertencessem às comunidades de Michoacán, para ressaltar sua legitimidade e enfatizar as raízes em

7. Na legislação mexicana não existe a noção de cartel como figura jurídica e analítica para designar organizações criminosas. Sua utilização estendida ocorreu através da propaganda das agências de segurança americanas desde os anos de 1980. No entanto, nem toda organização criminosa toma forma organizada de cartel. Na Colômbia, por exemplo, foi proposta uma nomenclatura que especifique juridicamente as atividades e a formação organizacional dos grupos criminosos, em conceitos como "gangues criminosas", "grupos armados organizados" ou "grupos criminosos organizados". Ocorre o mesmo com a noção de "crime organizado", o conceito técnico na legislação mexicana é "delinquência organizada" indicada na Lei Federal contra a Delinquência organizada de 1996. No entanto, "crime organizado" é um conceito utilizado e concordado na literatura sociológica. Aqui me referirei a organizações criminosas ou grupos criminosos.

8. O Cartel do Golfo incorporou o repertório paramilitar baseado no terror, sob a direção de Osiel Cárdenas. Essa forma de operação foi apropriada pelas demais organizações antagonistas. 
seus conterrâneos, em contraposição com Os Zetas. Um modo de operação, que foi conservado pelos Zetas, foi a cobrança por proteção. No entanto, eles levaram essa ação a outro nível, ao estabelecer uma ordem parafiscal que se apropriou, inclusive, de uma porcentagem das despesas correntes dos municípios do estado. Outro grupo importante foi Os Cavaleiros Templários, que surgiu como uma remoção da Família Michoacana em 2011 e que operou com base em uma diversificação de atividades criminosas com altas margens de ganhos, como o contrabando de minerais e de madeira. Essa organização é importante porque não só funcionou como um grupo de extração, mas também, basicamente como uma organização que procurava uma reorganização social e moral fundamentada em preceitos místicos. Todos esses grupos estabeleceram uma ordem criminosa através do terror, disputando a legitimidade do monopólio da violência e aproveitando o excesso de força de trabalho da população rural residual, que se uniu às organizações criminosas.

Nas décadas de 1990 e 2000, com um aprofundamento das políticas neoliberais, em Michoacán ocorreu uma transformação estrutural da economia regional, pela reestruturação produtiva em sua vocação agrícola, deslocando cultivos tradicionais como a cana de açúcar e o milho, em favor do de frutas vermelhas (amora, mirtilo e morango) e abacate em importantes regiões agroexportadoras do ocidente do estado. Essa reestruturação produtiva transformou a paisagem e a economia regional, reconcentrando a renda e gerando um profundo acúmulo de capital nas áreas agrícolas. Além disso, surgiram problemas ambientais em relação com recursos hídricos e controle de pragas. Isso acabou gerando tensões entre comunidades pela escassez de água e um realinhamento das relações de poder entre comunidades ${ }^{9}$. Essa transformação também ocorreu nas dinâmicas dos grupos de narcotráfico na região, que diversificaram suas atividades dirigindo-as ao tráfico de drogas sintéticas e que viram na nova reestruturação produtiva uma oportunidade para expandir a renda de suas atividades criminosas através da extorsão.

Reconversão produtiva e mudança na função do narcotráfico se entrelaçaram em uma relação complexa que estabeleceu as bases para a transformação regional rumo à violência difusa, ao impulsionar uma forma de apropriação de renda que modificou a antiga relação de equilíbrio entre a ilegalidade e as comunidades, gerando uma ordem criminosa.

9. Conflitos em torno do fornecimento da água surgiram na região montanhosa do município de Los Reyes, onde comunidades, como Pamatácuaro e Oruzcato, ficaram em uma situação trágica, especialmente porque as nascentes de água foram destinadas à irrigação de abacate e frutas vermelhas. Não é coincidência que uma das demandas dos grupos de polícias comunitárias da região, para aceitar a legalização em 2014, tenha sido a perfuração de poços de água (Trabalho de campo, Los Reyes, 2015). 


\section{Segurança e Extorsão}

Uma característica da operação das organizações criminosas foi a diversificação de suas atividades lucrativas. Entre elas, a cobrança por proporcionar segurança tem sido uma prática estendida em uma série de contextos diversos, como documentado nos casos das gangues criminosas na Colômbia (Medina, 2015), dos empresários violentos na Rússia após a queda do regime soviético (Volkov, 2002), das milícias armadas no Rio de Janeiro e do Primeiro Comando da Capital nas favelas de São Paulo (Gledhill, 2016).

Essa prática de cobrar tarifas por proteção foi estendida pelos Zetas em sua invasão em Michoacán e posteriormente retomada pelas organizações seguintes. Os Cavaleiros Templários impuseram o pagamento de tarifas garantindo que protegeriam as comunidades dos abusos e assassinatos ocasionados pela Família Michoacana. Em anos anteriores, a Família havia imposto essa cobrança, argumentando o mesmo sobre os abusos dos Zetas.

Em um trabalho de campo, pude coletar um testemunho sobre esse sistema de extorsão baseado na tarifa por proteção. No povoado de La Ruana, uma residente comentou que as tarifas haviam sido toleradas porque quando foram impostas existia trabalho e não foi difícil pagá-las: "Eles vieram e disseram que iam cuidar de nós e por isto precisavam ter recursos para cuidar de nós... ninguém disse nada... o que aconteceu é que existia trabalho e não foi um problema contribuir, o problema é que começaram a cobrar cada vez mais" (Ana Flores, entrevista, La Ruana, 24 de fevereiro de 2014).

Durante a conversa, surpreendi-me com a normalidade com que se falava do pagamento. Revelava-se, assim, um tipo de disciplinamento assimilado para que fossem sujeitos à extorsão. Cada grupo havia se apresentado oferecendo proteção e garantindo ser menos criminoso que o anterior, estabelecendo a cobrança como uma normalidade e o pagamento como um destino.

Os Cavaleiros Templários articularam um regime de extorsão que impôs cargas parafiscais na atividade econômica local: cobranças por toneladas de cultivos colhidos para agroexportação (limão, abacate, amora) e por quilogramas para pequenos produtores e para produtos da cesta básica (ovo, tortilhas e carne), até pelas folhas de pagamento de trabalhadores e pelos recebimentos de pagamento por serviços públicos. Solicitaram, inclusive, contribuições em espécie. Uma anedota que me foi contada por uma professora de Tepalcatepec, dimensiona o acima exposto: "Um vendedor de iguanas contribuiu com oito por semana para o chefe de drogas local e um professor, que tinha experiência como cozinheiro de uma vez que emigrou para os Estados Unidos e trabalhou em um restaurante, foi retirado a força da sala de 
aula, em várias ocasiões, para ir cozinhá-las” (Julia Flores, Entrevista, Tepalcatepec, 22 de julho de 2014).

A tarifa por proteção supõe a construção de um controle territorial e uma ordem política que precisa adquirir meios econômicos para seu sustento. Isso leva a situar a legitimidade dessa ordem criminosa através da apresentação da renda de extorsão como tarifa pela segurança. Para sustentar essa ordem e o controle territorial, é necessário o uso de cobradores armados, que permanentemente a realizem, assegurando que não existam outros concorrentes dessa ordem ou que a disputem. A cobrança de extorsão se torna assim, um trabalho de período integral, que sustenta e reforça a paramilitarização. O termo, paramilitar, para referir-se aos cobradores armados, está em discussão, dado que provém da vinculação histórica com atividades contrainsurgentes na imposição de uma ordem político-ideológica perante os dissidentes, como na Colômbia. Para alguns pesquisadores, pode ser estendido aos grupos de crime cuja motivação não é já política, e sim econômica, já que continuam utilizando o conhecimento militar (Correa et al., 2015).

Deve ser observado que o regime de extração de renda de extorsão gera uma força reguladora por parte desses atores criminosos, estabelecendo um tipo de ordem, com sanções e recompensas, que disputa e complementa a soberania estatal em uma zona de indistinção entre criminalidade e Estado: em uma zona cinza (Fuentes Díaz, 2018). Isso revela uma nova morfologia do Estado ao menos no nível local, onde coexistem e disputam diferentes conexões do uso legítimo da violência e da regulamentação social.

\section{A zona cinza}

O conceito de zona cinza é inspirado aqui na maneira como Auyero (2007) o usa, com base em sua leitura de Primo Levy, para referir-se a uma zona do espaço social na qual se dissolvem os limites normativos. Para Levy (1998), diz Auyero, a experiência do campo de concentração é a de uma zona de ambiguidade que desafia a divisão bipartidária entre nós-eles/amigo-inimigo. Por essa razão, é útil como uma ferramenta conceitual, para pensar nas zonas do espaço social que misturam práticas de maneira indistinta ( para o caso deste estudo, o normativo com o ilegal) e recorda a noção de indistinção que Agamben (1998) utiliza para referir-se ao estabelecimento de regimes soberanos em que a lei e a exceção se confundem.

Para Agamben a noção de indistinção se refere ao tempo em que o estado de exceção coexiste com o Estado de Direito, sob a suspensão dos direitos individuais, sem qualquer mediação jurídica, em que a vida é colocada em um interregno legal. No entanto, o sentido da indistinção, que se deseja enfatizar neste artigo, é aquela 
parte do espaço social em que a legalidade e a exceção se mesclam de uma forma prática, para erguer uma ordem política através da indistinção entre atores estatais e atores criminais. Esse apagamento define grandes áreas da política local em Michoacán, onde não há separação ou oposição entre legal e ilegal, formal e informal, Estado e crime, mas sim, uma fusão eficaz e funcional para a governança local em composições políticas criminosas que exercem o governo. Poder-se-ia dizer que o governo é feito através da exceção.

Nesse sentido, é evidente, nos termos etnográficos abrangidos pelo presente estudo, a indistinção dos estados de exceção que Agamben teoriza: além da suspensão de garantias individuais, temos um funcionamento eficaz de exercício da soberania que mistura legalidade e ilegalidade, em uma área que se torna funcional para acumulação de capital. Para dar uma precisão fenomenológica dessa indistinção, a noção de zona cinza é utilizada.

Eu não uso a categoria de margem do Estado (Das e Poole, 2004) para caracterizar esses interregnos legais, devido à imprecisão conceitual que ela lança. A despeito do esforço dos proponentes dessa categoria, para se distanciar da imagem de centro e periferia que a noção de margem implica, subjaz uma dicotomia que opõe uma centralidade adequada e funcional a uma esfera borrada de práticas políticas não reguladas e legitimadas pela lei. É por isso que o termo que define mais claramente essa relação oscilante de ambiguidade e excepcionalidade não-dicotômica é a zona cinza.

Nessa zona cinza, a extorsão deve ser entendida como uma extensa cadeia de extração de valor agregado em um circuito de valorização de mercadorias legais e ilegais, em que o uso da força por parte dos grupos criminosos, converte-se em um elemento central da produção, gerando reordenamentos locais de poder através da coordenação de atividades econômicas e políticas, desdobrando funções de segurança, matando ou permitindo viver, em outras palavras, realizando funções de governo. Esses eventos se referem a esta área de continuidade e indistinção que estudou Tilly (2007), entre Estado e crime organizado, para gerar a ordem política europeia no século XVII. Para Tilly, a origem do Estado não se diferencia da atividade criminosa e, para isso, a extração a segurança se constituem como um par estratégico fundamental para gerar ordens políticas e fiscais através do recurso da força ${ }^{10}$. A utilização do par segurança-

10. "Os raciocínios enfatizam a interdependência entre [...] a construção do estado [...] e o que se denomina crime organizado [...] Da mesma forma, a delinquência, a pirataria, a rivalidade criminal, a conservação da ordem pública, e a guerra todos pertencem a esta mesma realidade [...] A fina e fraca linha que separa a violência 'legítima' e 'ilegítima' apareceu nos níveis mais altos do poder [...] No serviço real, se esperava dos soldados e marinheiros que se sustentassem sozinhos às custas da população civil: se apropriando, violentando, saqueando [...] Quando eram desativados, continuavam com as mesmas práticas, mesmo sem a proteção real: os navios desativados se tornavam navios piratas; as tropas desativadas, em bandidos" (Tilly, 2007, pp. 3-6). 
-extração, pelas organizações criminosas em Michoacán, refere-se à construção de uma nova soberania, na qual o governo da população opera em uma zona em que a ordem criminosa estabelecida não se distingue das instituições do Estado.

Por outro lado, as disputas pelo controle dos Templários, em comparação com outros grupos, utilizou a violência sexual. Em minhas entrevistas em campo, as entrevistadas relataram que a violência sexual contra as mulheres foi uma ofensa intolerável. "O que não aguentava mais eram os estupros das nossas garotas, até as mulheres casadas tinham que ter relações forçadas, porque eram eles (Os Templarios) que mandavam e intimidavam, 'se você não está comigo eu mato seu pai ou sua família”" (Laura Hernández, entrevista, Tepalcatepec, julho de 2014).

Como indica Segato (2013), o corpo feminino é utilizado como uma tela sobre a qual registrar a derrota moral do inimigo. Dessa maneira, o uso da violência sexual contra as mulheres deve ser entendido como um indicador do estabelecimento de uma ordem criminosa que utiliza essa marcação dentro de uma pedagogia expressiva do uso da força. Assim, regime extorsivo, violência sexual e assassinatos foram os detonadores para a quebra do equilíbrio e da legitimidade histórica entre o narcotráfico, as comunidades e o Estado. Em trabalho de campo, o dia em que o governo federal recapturou pela primeira vez Chapo Guzmán, líder da organização de Sinaloa, um membro do grupo de autodefesas em Peribán me referiu a diferença entre as formas de operação legítimas e as extorsivas, que quebrantaram a reciprocidade entre o tráfico e as comunidades: "Estes caras [Os Templários] não tem nenhum respeito. Estão sempre extorquindo, não são como o Chapo. Ele sim era um Senhor" (Juan Luis Reyes, entrevista, Peribán, 26 de julho de 2014). Esse comentário revela a quebra da ordem local com a perda de reciprocidade e legitimidade de uma relação de clientes entre os traficantes de drogas e as comunidades. Não foi contra o narcotráfico que surgiu a defesa comunitária, mas sim contra a extorsão, os assassinatos, os estupros e os saques que quebraram a reciprocidade.

Com isto foi criada a defesa comunitária nas formas de polícia comunitária e grupo de autodefesa; bem como uma terceira forma ainda pouco estudada, através da criação de grupos civis armados, contratados por empresários agrícolas para trabalhos de segurança nas fazendas, organização intermediária entre a segurança privada e o paramilitarismo ${ }^{11}$ (Gráfico 2).

11. O terceiro grupo é constituído por profissionais pagos por particulares e treinados por agentes de segurança do Estado. O Corpo de Segurança de Tancítaro seria um exemplo. Com formação militarizada, capacitados pelo Grupo de Operações Especiais da Polícia Federal, respondiam no início a um comando privado realizando atividades de patrulha, dissuasão, e trânsito (Trabalho de campo, Tancítaro, Michoacán, agosto de 2016). 
GRÁFICO 2

Defesas Comunitárias em Michoacán

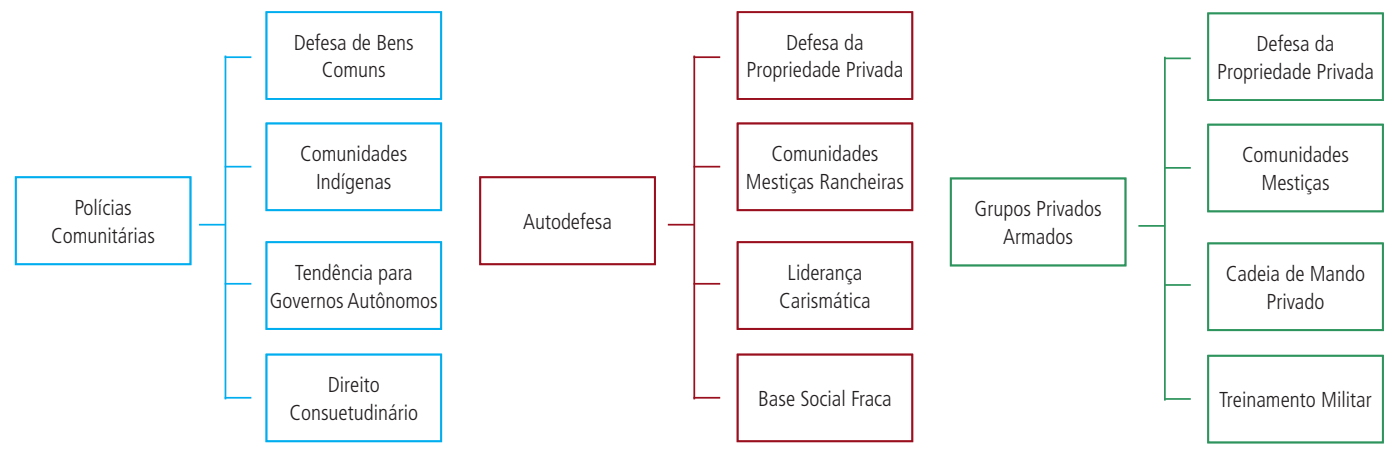

Fonte: Elaboração própria.

\section{Autodefesas na Tierra Caliente}

Michoacán possui extensas áreas dedicadas às exportações agrícolas. A vinculação dos Cavaleiros Templários com as atividades comerciais formais e com a economia ilegal local, através da lavagem de dinheiro e da extorsão, levou-os a controlar a comercialização dos principais cultivos de agroexportação, como o abacate na região central do estado e as frutas vermelhas no oeste. No município de Buenavista, eles decidiam de qual produtor comprar e qual bloquear, o que foi gerando um clima de inconformidade acompanhado pelo descontentamento com o regime extorsivo. Em Tepalcatepec, município adjacente a Buenavista, a situação de extorsão, violência sexual e bloqueio da comercialização foram as mesmas que em outras zonas. As cinco empresas mineiras estabelecidas nesse município foram extorquidas com uma cobrança de US\$ 6 por tonelada em volumes de 400 toneladas por semana e o preço do gado estava sujeito a um imposto de 30 por cento. $\mathrm{O}$ cansaço com essa situação detonou o movimento regional de civis armados que confrontou os Cavaleiros Templários em 24 de fevereiro de 2013.

Os grupos de autodefesa se caracterizaram pelo surgimento no marco das rivalidades entre grupos criminosos antagônicos para tomar o controle regional do comércio de substâncias ilegais. Nesse sentido, o movimento de autodefesas foi completo porque combinou o descontentamento com os abusos dos Templários, com uma mudança nos beneficiários da concessão do lugar. De acordo com minhas entrevistas, os grupos de autodefesa tinham dois objetivos: dar um fim à violência è̀ extorsão e ganhar o patrocínio de um novo grupo criminoso, que proporcionou armas à autodefesa e que, eventualmente, seria o beneficiário da queda dos Templários. 
Legalização e policiamento dos grupos de defesa comunitária

No início de 2014 foi coordenada uma estratégia de contenção dos grupos de defesa em Michoacán como política de Estado. Para tanto, o governo federal designou uma Comissão especial para a Segurança e o Desenvolvimento Integral de Michoacán, que tomou controle do poder executivo do estado e que impulsionou a via da legalização dos grupos de defesa (tanto polícias comunitárias como grupos de autodefesa), dentro da figura de Corpos de Defesa Rural (Ramos, 2014). Dessa maneira foi criada a quarta figura, que não existia naquele momento, dentro do organograma dos corpos policiais de segurança pública no México: um corpo de Polícia Força Rural que estaria subordinada à Secretaria de Segurança Pública do Estado de Michoacán ${ }^{12}$.

Em sua implementação, a Força Rural teve questionamentos de vários membros dos grupos de autodefesas e das polícias comunitárias que não se incorporaram e que afirmavam que nele haviam se infiltrado antigos membros dos Cavaleiros Templários ou de outros grupos criminosas, os chamados "arrependidos", que dessa maneira voltavam agora, com licença oficial, para as atividades criminosas, como a extorsão e a fabricação e comercialização de metanfetamina.

Em 10 de maio de 2014, em Tepalcatepec, lugar simbólico por ser origem da rebelião e por ser lugar estratégico pela história local vinculada ao tráfico de substâncias ilegais, o titular da Comissão especial para a Segurança e o Desenvolvimento Integral de Michoacán pronunciou, no juramento aos novos membros da Força Rural, uma frase que hoje possui uma maior ressonância sobre as disputas na zona cinza: "hoje, o Estado são vocês" (Martínez, 2014).

Para algumas interpretações (Gil, 2015; Lemus, 2015), o surgimento dos grupos de autodefesa e sua legalização foram uma estratégia orquestrada como política de segurança pelo governo federal para enfrentar os Templários e proporcionar uma mudança de beneficiários das atividades criminosas. Embora essa interpretação simplifique o papel de outros grupos defensivos como as polícias comunitárias, o que pode ser resgatado é que aponta para a articulação de uma zona de ambiguidade que, da perspectiva aqui argumentada, estabelece um rumo em direção à coprodução da segurança em uma zona de indistinção, em que organizações de vigilância e segurança paralegais coadjuvaram, em um determinado momento, com forças militares e federais para captura dos líderes dos Cavaleiros Templários.

Um exemplo de tal mecanismo foi a criação do grupo de elite G-250, integrado tanto por pessoal militar e da polícia federal, como por membros das autodefesas,

12. São três os corpos que constituem o esquema policial no México: Polícia Federal, Polícia Estadual e Polícia municipal; a Polícia Força rural, criou um quarto corpo. 
GRÁFICO 3

Estratégia de Legalização do Governo Federal dos Grupos de Defesa Comunitária

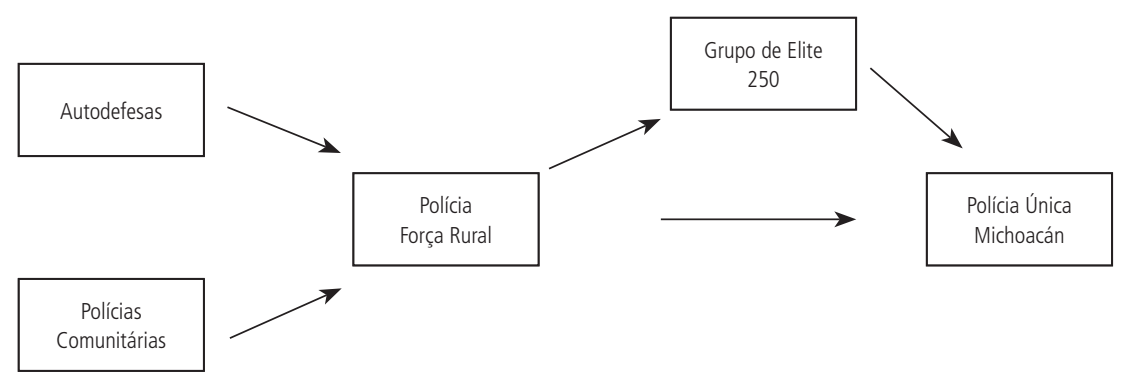

Fonte: Elaboração própria.

que previamente haviam pertencido a organizações rivais dos Templários como Os Viagras, os H3 (Terceira Irmandade) ou que tinham sido membros "arrependidos" do grupo agora perseguido (Notas de trabalho de campo, Buenavista, Michoacán, agosto 2015). Disso se entende que a aposta do governo federal foi encontrar figuras legais e âmbitos institucionais que enquadrassem essas formas comunitárias de participação, apesar disso envolver a movimentação em uma zona cinza de indistinção legal-paralegal (Gráfico 3).

Cabe mencionar que vários corpos de autodefesa, sobretudo na zona da costa, não se incorporaram ao processo de legalização e estavam relutantes em formar parte da Força Rural; vários líderes que resistiram a essa incorporação foram presos e outros foram assassinados. Por outro lado, anteriores grupos de polícias comunitárias já existentes como as de Cherán e Nurio, não participaram da Força Rural, dado que suas organizações defensivas contavam com reconhecimento legal como povoados originários. Em abril de 2016, o governo do Estado de Michoacán, considerou extinta a Força Rural e seus membros foram encaminhados a um novo corpo policial do estado, denominado Polícia Única de Michoacán, formado por 561 elementos procedentes da Força Rural (Pacheco, 2016). O processo de legalização envolveu o esvaziamento de um movimento comunitário defensivo, detonado com a situação de insegurança gerada pela omissão estatal e o ataque criminoso, para uma forma de policiamento oficial. Foi feita a tentativa, desse modo, de que um movimento perturbador, completo e polifônico fosse reduzido a uma expressão policial. A situação, no entanto, continua sendo complexa já que, apesar da criação desta Polícia Única Michoacán, subsistem nos dias de hoje vários grupos de civis armados que não aceitaram a legalização estatal, ou que não aprovaram os controles de confiança para participar de tal corpo de polícia do estado. 


\section{Defesa comunitária e segurança no neoliberalismo}

Estudos sobre a segurança no México a partir da "Guerra contra o narcotráfico" documentaram o deslocamento da política de segurança do Estado para um ambiente mais punitivo, através da reforma Constitucional em Matéria de Justiça Penal e Segurança Pública aprovada em 2008, que na modificação da Lei Federal contra o Delinquência Organizada permitiu na prática a criminalização do protesto.

No entanto, como indicado, as comunidades reagem não só contra os ataques das políticas de segurança do Estado, mas também contra os ataques de outros atores não estatais com capacidade de força, como o crime organizado. Com isso, algumas respostas foram dadas através da instauração de ordens apropriados de regulamentação da segurança em seus ambientes locais. Uma ampla proliferação dessas ordens foi levantada com vigor desde os anos de 1990 em uma variedade de eventos, como linchamentos, vigilantismo e isolamentos habitacionais, que hoje se expressam através da defesa comunitária.

Considerando que o perigo e a falta de segurança não são consequências indesejadas ou efeitos negativos da economia neoliberal, mas parte inerente de sua implementação, tais ordens de regulamentação devem ser consideradas como parte da gestão governamentalizada de riscos diante da produção sistêmica de insegurança. A novidade a respeito da segurança, que as ordens apropriadas da regulamentação da segurança colocam em jogo, é a proliferação de múltiplos atores que exercem ações regulatórias. A apropriação da segurança não leva implicitamente à queda das competências reguladoras do Estado, mas a uma coexistência de múltiplos centros de onde se exerce controle. Janet Roitman (2004) documentou um fenômeno similar em sua pesquisa em Chad Basin, sob a noção de pluralização de autoridades regulatórias. Essa noção se refere à simultânea gestão de funções da segurança de distintos atores em um mesmo território.

Constituem-se assim novas formas de contenção do risco, possibilitadas em certa medida pela cessão, por parte do Estado, de funções de segurança, para fomentar uma maior participação dos cidadãos em tarefas de segurança $\mathrm{a}^{13}$. A hipótese desenhada é que a formação de defesas comunitárias se encaixa em uma ampla gama de práticas regulatórias, favorecidas pelo regime de veridicção neoliberal, referido à transferência para a gestão individual de funçôes que antes eram responsabilidades do Estado. Por exemplo, em Michoacán, durante o trabalho de campo realizado em 2013 e 2014,

13. A estratégia de segurança cidadã, implementada desde os anos de 1990 no México, tem sido sob a tese da coprodução da segurança. Um dos programas mais extensivos tem sido o "Vizinho vigilante", que consiste no envolvimento dos cidadãos na vigilância e denúncia de delitos, formando comitês de vizinhos. 
fui orientado em várias ocasiões a parar em distintos postos de revisão nas zonas de estudo. Eram postos de controle formados por Autodefesas e Polícias comunitárias que coexistiam com postos de controle dos agentes do Estado: Polícia Estatal, Polícia Federal, Exército. Todas essas autoridades regulatórias oficiais e paraestatais se encontravam em coexistência espacial exercendo ações de segurança contra o crime organizado, muitas vezes com funções contrapostas.

\section{Checkpoint}

Refletir sobre os postos de verificação e checagem (checkpoint) é interessante porque eles se constituem em limites territoriais nos quais as fronteiras entre legal e ilegal encontram-se borradas. No início de 2013, uma estratégia ilegal para conter a entrada de grupos criminosos nas comunidades consistia na colocação de postos de verificação e checagem nos acessos a estradas em pequenas cidades e vilas rurais. $\mathrm{O}$ posto de verificação começou ao cortar a estrada com pedras e tábuas com pregos. Uma vez parados os veículos, os motoristas eram inspecionados e questionados sobre o seu destino e o motivo da viagem, os veículos eram examinados e observava-se de modo desafiador e desconfiado os viajantes. Aqueles que faziam as inspeções revisão eram homens adultos, mas também havia jovens entre 15 e 18 anos. Os inspetores estavam armados com facões, paus e espingardas e, em alguns casos, como em Los Reyes, Peribán e Tierra Caliente, carregando fuzis AK-47 e R-15, entre outros. No começo, eles usavam lenços ou balaclavas que lhes permitiam esconder o rosto e a identidade, não havia como saber realmente quem eles eram. Em várias ocasiões, pude verificar que bebidas alcoólicas foram consumidas nos postos de verificação e as inspeções foram realizadas sob embriaguez.

Eventualmente, alguns postos de verificação passaram de barricadas simples, com pneus e veículos queimados como contenções, a edifícios formais com arquitetura técnica adequada para vigilância: edifícios de pedra em dois níveis com medidas especiais para resistir a diferentes diâmetros de balas; câmeras de vigilância; comunicação de rádio e luminárias potentes.

De acordo com Jeganathan (2004), quem estudou o uso de checkpoints em Sri Lanka, no contexto da guerra civil entre o separatismo Tamil e o governo, o ponto de verificação deve ser entendido como uma manifestação da insegurança e incerteza estrutural e global, tornando-se uma tecnologia apropriada para antecipar possíveis ações de violência e uma implantação tática do Estado para contê-la. Sua presença supõe um governo da insegurança em ambientes violentos.

Em Michoacán, uma diferença substancial em relação à pesquisa de Jeganathan é que o checkpoint foi feito por comunidades organizadas ou agentes privados, mas 
não pelo Estado, por isso seu uso esteve ligado à falta de cobertura de segurança do Estado, e esse seu papel ambíguo o tornou um fator de insegurança. Dessa forma, o checkpoint se refere a um novo tipo de gerenciamento de risco que envolve a participação de atores não estatais na segurança através da regulação em zonas cinzas. A presença dos checkpoints marca o fim do controle do Estado e o início de um controle diferente gerado por atores privados ou comunidades apropriando-se da segurança, movendo-se em direção a novas formas da governamentalidade do risco (Foucault, 2006).

De acordo com Jeganathan (2004), o checkpoint deve ser entendido como a arquitetura epistemológica da modernidade, uma vez que o verificado tem que provar a sua inocuidade baseada em ser legível como não perigoso, o que coloca em jogo questões de identidade sociais e políticas, no momento da verificação, com as quais o Estado identifica seus cidadãos (subjetivação). No entanto, para o caso estudado neste artigo, o ponto de verificação é focado em um dispositivo da arquitetura descentralizada e móvel não conformado para a produção de sujeitos ou seu governamento estatal (Foucault, 1993) ${ }^{14}$, mas para sua regulação por atores não estatais (comunitários ou privados). Nessa regulação, o checkpoint filtra a circulação de produtos ilegais e agentes criminosos nos territórios segurados, gerando ilhas de segurança nos lugares que os rotinizaram. Ao fazer isso, divide os cidadãos em vizinhos e estranhos e, de maneira acentuada, entre bons e ruins ${ }^{15}$, separando a ordem criminosa-estatal (o exterior), da nova ordem imaginária construída sob a apropriação de segurança (o interior), reforçando assim o sentido de uma comunidade defensiva e fechada. Ao contrário do estudo da Jeganathan, em Michoacán o checkpoint não pode ser considerado como uma margem do estado fluido e móvel, mas a manifestação de uma zona cinza, uma apropriação do controle e regulação além da gramática do Estado, uma tecnologia para regular a mobilidade e conter as ameaças.

\section{Regulações múltiplas}

Essa pluralidade de autoridades regulatórias em sua expressão paraestatal se caracteriza por disputar com o Estado a legitimidade no uso da violência, através da instauração de ordens comunitárias de regulamentação da segurança, que em alguns casos se dirigem ao estabelecimento de sistemas de justiça e estruturas próprias de governo, instituídos fundamentalmente pela percebida omissão das agências do

14. Nesse sentido, compartilha com o muro o propósito da contenção através da separação espacial. As cidades dos muros, a forma gueto e os muros da fronteira seriam a nova arquitetura da regulação.

15. Em Michoacán, a maneira coloquial de se referir aos membros do crime organizado é como "ruins". 
Estado em proporcionar ambientes seguros, quando não em sua cumplicidade direta com o crime.

Por isto, a defesa comunitária se levanta em um processo duvidoso e duplo disputado na zona cinza: por um lado, contra o crime organizado e sua atividade usurpadora, por outro, fazendo frente ao Estado e sua intenção de ilegalizá-la e desarmá-la. Mas fundamentalmente, levanta-se contra a ordem criminosa que, no plano local, tem sido produzida pela indistinção entre Estado e crime.

Por sua vez, vemos que as estratégias defensivas desses grupos também surgem na zona cinza, suspendendo ou restabelecendo a lei num sentido oportuno da conjuntura. Por exemplo, no município de Cherán, sua insurreição armada dissolveu a estrutura municipal e o sistema de partidos políticos, apelando à lei para estabelecer uma nova ordem sob a criação de um Conselho Comunal que substituísse o município como uma figura de representação territorial. Aragón (2015) documentou a importância dessa estratégia jurídica, utilizando simultaneamente a estratégia política. Em Tierra Caliente, a ordem criminosa predatória que era indistinguível da legalidade foi suspensa pela força das armas e se apelou a lei para tentar dar legitimidade aos grupos defensivos sob o nome de autodefesa.

Nessas experiências, vemos as oscilações entre ilegalidade e legalidade, que foram utilizadas pelas comunidades levantadas para destituir a ordem criminosa. Nessa zona cinza, a estratégia armada ilegal resultou ser necessária para impugnar a ordem criminosa local e logo se apoiar na lei para instaurar um novo imaginário de ordem (Escalona, 2011). Nessas experiências concretas, que parecem invocar as teses sobre a violência de Walter Benjamin (2007), encontramos estratégias duvidosas na zona cinza, em que o recurso à lei busca voltar a dar significado e jogar contra-hegemonicamente (Aragón, 2015). Como defende Agamben (1998), o Estado de exceção é aquele onde a lei vigente perdeu significado e onde a exceção e a legalidade se confundem. Podemos sugerir que a ordem política criminal estabelecida em Michoacán na zona cinza funcionou como um estado de exceção. Diante disso, o surgimento de grupos defensivos pode ser entendido como um movimento armado que tentou dar um novo significado à lei ao subverter a ordem criminal local.

\section{Conclusões}

O estado de Michoacán possui uma história de atividades ilegais permitidas ou toleradas pelo governo. Essas atividades haviam sido associadas com os narcotraficantes e estavam baseadas no respeito à base social, códigos de honra em seu exercício, obra pública e certo grau de regulamentação por parte das instituições estatais. A nova forma de operação do crime organizado que interrompeu essa ordem foi uma res- 
posta às mudanças estruturais na economia regional e à descentralização por parte do Estado. A mudança nas exportações agrícolas ofereceu aos grupos criminosos a oportunidade de diversificar suas atividades ilegais através da extorsão baseada no despotismo tributário e o controle territorial incluindo a violência sexual. $\mathrm{O}$ crime organizado passou a formar parte da estrutura formal do Estado, tanto no nível municipal como estatal, operando em uma área de exceção - uma zona cinza entre a legalidade e a ilegalidade - na qual desempenhava funções estatais. $\mathrm{O}$ surgimento de grupos de autodefesa foi uma resposta a essa situação e talvez a única opção das comunidades para resistir aos grupos criminosos, dado o abandono pelas autoridades de seu papel de proteger a cidadania. Os grupos de autodefesa se opuseram tanto à ordem paraestatal local do crime organizado como ao estado central que exigia seu desarmamento e dissolução. As comunidades se apropriaram da força, da segurança e da justiça, gerando um novo imaginário de ordem social oposto à ordem criminosa nesse terreno excepcional.

\section{Referências Bibliográficas}

Agamben, Giorgio. (1998), Homo sacer: el poder soberano y la nuda vida. Madri, Pre- Textos. Aragón, Orlando. (2015), “A disputa pela diversidade jurídica nos tempos da globalização: a propósito, poderá o direito ser emancipatório?”. Direito y Praxis, 6 (10): 261-309.

Astorga, Luis. (2015), Qué querían que hiciera: inseguridad y delincuencia organizada en el gobierno de Felipe Calderón. México, Grijalbo.

Auyero, Javier. (2007), La zona gris. Buenos Aires, Siglo XXI.

Benjamin, Walter. (2007), "Para una crítica de la violencia”. In Benjamin, Walter. Conceptos de filosofía de la historia. Buenos Aires, Terramar, pp.113-138.

Calderón, Marco. (2001), "Lázaro Cárdenas del Río en la Cuenca del Tepalcatepec-Balsas”. In: Zarate, Eduardo (ed.). La Tierra Caliente de Michoacán. México, El Colegio de Michoacán A. C./Gobierno del Estado de Michoacán, pp. 233-265.

Correa, Guadalupe et al. (2015), "Losing the monopoly of violence: the State, a drug war and the paramilitarization of organized crime in México (2007-2010)". State Crime Journal, 4 (1): 77-95.

Das, Veena \& Poole, Deborah. (2004), Anthropology in the Margins of the State. Santa Fe, Sar Press.

Escalante GonZalbo, Fernando. (2011), “La muerte tiene permiso”. Nexos, 1 (397): 36-49.

EsCALONA, José Luis. (2011), "El incompleto imaginario del orden, la inacabada maquinaria burocrática y el espacio de lucha: antropología del Estado desde el sureste de México”. In: Agudo Sanchíz Alejandro \& Estrada, Marco (eds.). (Trans)formaciones del Estado en 
los márgenes de Latinoamérica. México, El Colegio de México/Universidad Iberoamericana, pp. 45-86.

FLores, Carlos. (2009), El Estado en crisis: crimen organizado y politica, desafíos para la consolidación democrática. México, Ciesas.

Foucault, Michel. (1993), Vigilar y castigar: nacimiento de la prisión, México, Siglo XXI.

Foucault, Michel. (2006), Seguridad, territorio y población. Argentina, Fondo de Cultura Económica.

Fuentes Diaz, Antonio. (2015a), "Violencia criminal y defensa comunitaria en Michoacán”. In: Fuentes Diaz, Antonio. Conflictos y sujetos emergentes: episodios en la transformación rural neoliberal. México, BUAP, pp. 75-101.

Fuentes Diaz, Antonio. (2015b), "Narcotráfico y autodefensa comunitaria en 'Tierra Caliente', Michoacán, México”. Cienciauat, 10 (1): 68-82.

Fuentes Diaz, Antonio. (2018), “Community defense and criminal order in Michoacán: contention in the grey area". Latin American Perspectives, 45 (6): 127-139.

Gibson, Edward. (2013), Boundary control: subnational authoritarianism in federal democracies. Cambridge, Cambridge University Press.

GiL, José. (2015), Batallas de Michoacán: autodefensas, el proyecto colombiano de Peña Nieto. México, Proceso.

GLedHILl, John. (2016), La nueva guerra contra los pobres: la producción de la inseguridad en Latinoamérica. Barcelona, Ediciones Bellaterra.

GrILlo, Ioan. (2011), El Narco: inside Mexico's criminal insurgence. Nova York, Bloomsbury Press.

Guerra, Enrique. (2017), “La violencia en Tierra Caliente, Michoacán, c. 1940-1980”. Estudios de Historia Moderna y Contemporánea de México, 53 (1): 1-17.

INEGI (Instituto Nacional de Estadística, Geografía e Informática). (2010), “XIII censo general de población y vivienda”. Disponível em http://www.inegi.org.mx/est/lista_cubos/consulta. aspx? $\mathrm{p}=$ pob\&c=1, consultado em 12/6/2013.

INEGI (Instituto Nacional de Estadística, Geografía e Informática). (2014), “Tasa de defunción por homicidios 1990-2011”. Disponível em http://www3.inegi.org.mx/sistemas/ biinegi/ ?ind=6200002200, consultado em 04/10/2014).

Jeganathan, Pradeep. (2004), “Checkpoint: Anthropology, Identity, and State”. In: Das, Veena \& Poole, Deborah. Anthropology in the margins of the State. Santa Fé, Sar Press, pp. 67-80.

Lemus, Jesús. (2015), Tierra sin Dios: crónica del desgobierno y la guerra en Michoacán. México, Grijalbo.

Levi, Primo. (1988), The drowned and the saved. Nova York, Summit Books.

Martinez Elorriaga, Ernesto. (2014), "La gente no se levantó contra el Estado, sino para solicitar su presencia: Castillo". La Jornada, p. 3, 11 maio.

Medina Gallegos, Carlos. (2015), "Bandas criminales y neoparamilitarismo en Colombia”. 
In: Zavaleta Betancourt, Alfredo (coord.). El laberinto de la inseguridad ciudadana. Buenos Aires, Clacso-UaCJ, pp.19-42.

Meyer, Jean. (1987), “Los 'Kulaki' del ejido (los años 30). Relaciones, 29 (8): 23-43.

Pacheco, Juan. (2016), "Dan de alta a 561 elementos de la extinta Fuerza Rural”. Disponível em https://www.quadratin.com.mx/justicia/Dan-alta-561-elementos-la-extinta-Fuerza-Rural/, consultado em 12/4/2016.

Ramos, Jorge. (2014), “Pactan legalizar las autodefensas”. El Universal. Disponível em http://m. eluniversal.com.mx/notas/nacion/2014/pactan-legalizar-las-autodefensas- 982975.html, consultado em 14/4/2015.

Ravelo, Ricardo. (2009), “La consolidación”. In: Rodrígues Castañeda, Rafael. (ed.). El México narco. México, Planeta, pp.13-21.

RnPed (Registro Nacional de Personas Extraviadas y Desaparecidas). "Estadísticas y notas metodológicas”. Disponível em http://secretariadoejecutivo.gob.mx/rnped/consulta-publica. php, consultado em 12/4/2016.

Roitman, Janet. (2004), "Productivity in the margins: the reconstitution of state power in the Chad Basin". In: Das, Veena \& Poole, Deborah. Anthropology in the margins of the State. Santa Fé, Sar Press, pp. 191-224.

Schwartz, Ricardo. (1998), “DF. Radiografía del crimen”. La Crisis, 3 (140): 24-26.

SEGATO, Rita Laura. (2013), Las nuevas formas de la guerra y el cuerpo de las mujeres. Buenos Aires, Tinta Limón.

STARn, Orin. (1999), Nightwatch: the politics of protest in the Andes. Durham, Duke University Press.

Tilly, Charles. (2007), “Guerra y construcción del estado como crimen organizado”. Revista Académica de Relaciones Internacionales, 1 (5): 1-26.

VAldés, Guillermo. (2013), Historia del narcotráfico en México. México, Aguilar.

Volkov, Vadim. (2002), Violent entrepreneurs: the use offorce in the makig of Russian capitalismo. Nova York, Cornell University Press. 


\section{Resumo}

A zona cinza: ordem criminosa e autodefesa armada no México

Os grupos de autodefesa no estado de Michoacán, México, surgiram para opor-se à extorsão e à violência da ordem paraestatal local estabelecida pelo crime organizado. Sua formação supõe a produção de um imaginário de ordem que se opôs à ordem criminosa local, que desempenhava funções de governo, controle violento e extorsão, em uma área cinza entre a legalidade e a ilegalidade. Palavras-chave: Autodefesas; Crime organizado; Narcotráfico; Zona cinza; México.

\section{Abstract}

The gray zone: criminal order and armed self-defense in Mexico

The self-defense groups in Michoacán, Mexico, have emerged to oppose extortion and violence of the local parastatal order established by organized crime. Its formation supposes the production of an imaginary of order that was opposed to the local criminal order, which carried out functions of government, violent control and extortion, in a gray area between legality and illegality. Keywords: Self-defense; Organized Crime; Drug Trafficking; Gray Zone; Mexico.

Texto recebido em 12/12/2017 e aprovado em 24/7/2018.

DOI: 10.11606/0103-2070.ts.2019.141533

ANTONIO FUENTES DíAz é doutor em sociologia pela Universidade Nacional Autônoma do México (UNAM). Interessado no crime organizado, violência coletiva e as apropriações comunitárias de segurança. Professor e Pesquisador do Programa de Pós-Graduação em Sociologia do Instituto de Ciências Sociais e Humanidades "Alfonso Vélez Pliego" da Universidade Autônoma de Puebla (UAP, México).E-mail: anfudi@gmail.com. 